\title{
Trends and attitude of edentate patients towards conventional and implant rehabilitative therapies: An Indian outlook
}

Sir,

Teeth play a vital role in the maintenance of a positive self-image and outlook that is why event of loss of teeth results in considerable disabilities, which can intensely interrupt social activities and quality of life. World Health Organization has clearly reported that "people rarely visit the dentist and only in the event of pain, as oral rehabilitation is restricted to the necessity." ${ }^{[1]}$ Complete edentulism is the end result of a multifactorial process involving biological factors and patient-related factors. It is the major problem in the developing countries and is widely spread in the current population although the prevalence is declining and incidence of tooth loss is decreasing in the developed nations like India. ${ }^{[2,3]}$ The overall rate of total edentulism is said to be increasing in developing countries chiefly due to the high prevalence of periodontal diseases and caries. This relative non-homogeneous allocation and prevalence of complete edentulism between developed and less developed countries is frequently associated with interrelated interaction between cultural, individual, attitude, behavior, dental attendance, etiopathogenesis of edentulism, access to care and socio-economic factors. ${ }^{[4]}$

However, this dilemma has also been tackled meticulously in the developing nations including India where its prevalence varies from $60 \%$ to $69 \%$ of 25 years and above age group, whereas $30 \%$ of edentulism is commonly seen in the age group of 25 years. ${ }^{[5]}$ This seems to be directly associated with the number of lost teeth, which increases with age, leading to an increase in prevalence edentulous patients. Furthermore, complete edentulism is on the rise in Indian populace predominantly due to inappropriate oral hygiene and tobacco-chewing habits. It generally strikes post 45 years of age and is classified as a physical handicap by the World Health Organization because it severely negatively affect speech, chewing ability, and normal facial structure.

In this modern era, the individual's attitude towards tooth loss is rapidly changing that solely includes greater expectations of their dental health than in the past. Literature has evidenced a number of non-pathologic associated with these conditions such as attitude, behavior, characteristics of the health care system, economical and occupational status. ${ }^{\left[{ }^{[6]}\right.}$ In spite of the fact that implant-supported complete denture provide immense improvements in implant-related surgical/prosthetic predictability, increased long-term clinical success, and enhanced patient education and acceptability for replacing missing dentition, conventional removable dentures continue to represent the first rehabilitative option offered to the edentate in many places around the World including Indian province. However, it restore only ten percent of chewing ability and lead to jaw bone degradation, whereas implant-supported/retained dentures can restore from 60 to 80 percent of chewing ability and patients do not experience any bone shrinkage. So, considering the overall state of affairs, it seems imperative for the leading dental practitioners in all populations around the Globe to gradually shift and modernize their conventional therapeutic philosophies what they offer and deliver to their completely edentulous patients.

\section{Sukant Sahoo, Prince Kumar, Karan Sethi,} Meenu Goel ${ }^{1}$

Department of Prosthodontics Shree Bankey Bihari Dental College and Research Centre, Masuri, ${ }^{1}$ Department of Orthodontics, Institute of Dental Studies and Technologies (IDST),

Modinagar, Ghaziabad, India

Address for the Correspondence:

Dr. Prince Kumar

Department of Prosthodontics,

Shree Bankey Bihari Dental College and Research Centre,

Masuri, Ghaziabad, India

E-mail: princekumar@its.edu.in 


\section{REFERENCES}

1. Shah N, Pandey RM, Duggal R, Mattur IP, Rajan K. Oral health in India: A report of the multicentre study ministry of health, Govt of India. WHO; 2007

2. Osterberg T, Carlsson GE, Sundh V. Trends and prognoses of dental status in the Swedish population: Analysis based on interviews in 1975 to 1997 by Statistics Sweden. Acta Odontol Scand 2000;58:177-82.

3. Awad MA, Lund JP, Dufresne E, Feine JS. Comparing the efficacy of mandibular implant-retained overdentures and conventional dentures among middle-aged edentulous patients: Satisfaction and functional assessment. Int J Prosthodont 2003;16:117-22.

4. Hugoson A, Koch G, Gothberg C, Helkimo AN, Lundin SA, Norderyd O, et al. Oral health of individuals aged 3-80 years in Jonkoping, Sweden during 30 years (1973-2003). I. Review of findings on dental care habits and knowledge of oral health. Swed Dent J 2005;29:125-38.

5. Felton DA. Edentulism and comorbid factors. J Prosthodont 2009;18:88-96.

6. Tramini P, Montal S, Valcarcel J. Tooth loss and associated factors in long-term institutionalised elderly patients. Gerodontology 2007;24:196-203.

\begin{tabular}{|c|c|}
\hline \multicolumn{2}{|l|}{ Access this article online } \\
\hline Quick Response Code: & \\
\hline \multirow{2}{*}{ 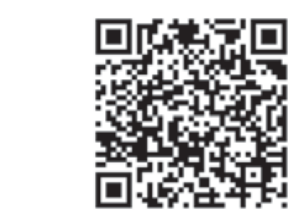 } & \\
\hline & $\begin{array}{l}\text { DOI: } \\
\text { 10.4103/2230-8598.115195 }\end{array}$ \\
\hline
\end{tabular}

